\title{
Lusioersily
}

\section{Every Minute Counts: Patterns and Times of Physical Activity Participation in Children From Socially Disadvantaged Areas in Ireland}

Belton, S., Breslin, G., Shannon, S., o'brien, W., Fitzpatrick, B., Haughey, T., Chambers, F., Powell, D., Mc Cullagh, D., \& Brennan, D. (2019). Every Minute Counts: Patterns and Times of Physical Activity Participation in Children From Socially Disadvantaged Areas in Ireland. Journal of Physical Activity and Health, 16(5), 333-339. https://doi.org/10.1123/jpah.2018-0368

Link to publication record in Ulster University Research Portal

Published in:

Journal of Physical Activity and Health

Publication Status:

Published (in print/issue): 01/05/2019

DOI:

10.1123/jpah.2018-0368

Document Version

Publisher's PDF, also known as Version of record

\section{General rights}

Copyright for the publications made accessible via Ulster University's Research Portal is retained by the author(s) and / or other copyright owners and it is a condition of accessing these publications that users recognise and abide by the legal requirements associated with these rights.

\section{Take down policy}

The Research Portal is Ulster University's institutional repository that provides access to Ulster's research outputs. Every effort has been made to ensure that content in the Research Portal does not infringe any person's rights, or applicable UK laws. If you discover content in the Research Portal that you believe breaches copyright or violates any law, please contact pure-support@ulster.ac.uk. 


\title{
Every Minute Counts: Patterns and Times of Physical Activity Participation in Children From Socially Disadvantaged Areas in Ireland
}

\author{
Sarahjane Belton, Gavin Breslin, Stephen Shannon, Wesley O’Brien, Ben Fitzpatrick, Tandy Haughey, \\ Fiona Chambers, Danielle Powell, Darryl McCullagh, and Deirdre Brennan
}

\begin{abstract}
Background: The purpose of this study was to investigate daily physical activity (PA) patterns of 8- to 9-year-old Irish children from socially disadvantaged areas. Methods: Children $(\mathrm{N}=408)$ were asked to wear an ActiGraph accelerometer for a minimum of 4 days. Based on mean daily moderate- to vigorous-intensity PA accumulation, participants were grouped into sex-specific quartiles (Q4, most active; Q1, least active). Principal component analysis was used to identify distinct time blocks for weekdays and weekend days. Results: Overall, 213 participants (8.7 [0.5] y) met accelerometer inclusion criteria. Of these, $56.7 \%$ met the 60 minutes of moderate- to vigorous-intensity PA per day guidelines, with males statistically significantly more likely to do so than females $(P<.01)$. Principal component analysis revealed 3 distinct time periods on weekdays and 4 distinct periods on weekends that children were active. The total difference in moderate- to vigorous-intensity PA accumulation between Q4 (most active) and Q1 (least active) was greatest in the after-school time period (male: 49 min and female: 33 min) on weekdays and in the evening time period on weekends (male: 33 min and female: 19 min). Conclusions: After-school and weekend evenings are critical "activity rich" time periods in terms of the gap between our most and least active disadvantaged children.
\end{abstract}

Keywords: health, monitoring, time period, weekday, weekend, socioeconomic status

Socioeconomic status (SES) refers to educational level, family structure, household income, and affluence of neighborhood. ${ }^{1}$ In children, low SES is suggested to be related to negative physical health markers including obesity ${ }^{2}$ and unhealthy lifestyle behaviors, such as malnutrition, low physical activity (PA), and sedentary behavior. ${ }^{3}$ The authors of the Growing Up in Ireland study ${ }^{4}$ highlighted gender and socioeconomic inequalities in health in Irish children and the potential link to higher levels of obesity. The Health Behaviour in School-Aged Children ${ }^{5}$ study also demonstrates that a greater proportion of Irish children from higher social classes report participating in vigorous exercise 4 or more times a week than children from less affluent social class groups. The Growing Up in Ireland study ${ }^{4}$ recommends that increasing rates of participation in sports and exercise among children from lower socioeconomic groups should be targeted.

The need for specific interventions to target PA during specific time periods for Irish children is highlighted in the recommendations of Woods et al. ${ }^{6}$ Before truly targeted intervention strategies can be developed, however, further information on the patterns of PA participation of younger children during specific time periods is needed. ${ }^{7}$ A number of international studies are worthy of note in this regard and are discussed below.

Using principal components analysis (PCA), Trost et $\mathrm{al}^{8}$ found that adolescents (12-16 y) weekday and weekend PA participation

Belton and Powell are with the School of Health \& Human Performance, Dublin City University, Dublin, Ireland. Breslin, Shannon, Fitzpatrick, Haughey, McCullagh, and Brennan are with Sport and Exercise Sciences Research Institute, Ulster University, Jordanstown, United Kingdom. O'Brien and Chambers are with Sports Studies and Physical Education Department, School of Education, University College Cork, Cork, Ireland. Belton (sarahjane.belton@dcu.ie) is corresponding author. each converged into 3 distinct time periods (weekday: 7-11.59 AM, 12-4.59 PM, and 5-8.59 PM; weekend: 8-11.59 AM, 12-4.59 PM, and 5-8.59 PM). Mota et al, ${ }^{9}$ using the same analysis, found that for 8- to 15-year-old children, weekday PA participation converged into 4 distinct time periods (10-12 PM and 2-7 PM, 12-2 PM and 7-9 PM, 9-10 AM, and 9-10 PM). These studies did not, however, investigate whether patterns of PA differed across these time blocks for high and low active children, for example, those exceeding the 60 minutes of moderate- to vigorous-intensity PA (MVPA) per day guideline ${ }^{10}$ and those falling far short of it. Knowing when the most active children partake in PA may prove valuable in helping practitioners develop interventions for those who are not as active. Fairclough et $\mathrm{al}^{11}$ categorized children (10-11 y old) into sexspecific quartiles based on their MVPA levels (Q1, least active; Q4, most active). They reported that children in Q1-Q3 were statistically significantly less active on the weekends than on weekdays, while children in Q4 maintained their PA levels consistently across weekdays and weekends.

Garriguet and Colley ${ }^{12}$ reported that for younger children $(6-10 \mathrm{y})$, the lunchtime period (defined as $11 \mathrm{AM}-1 \mathrm{PM})$ was the most active period of the weekday and that the most active tertile of children (based on MVPA accumulation) accumulated more MVPA in all periods of the day than the other 2 tertiles. (The school day was broken into seven 2-h blocks from 7 AM to 9 PM.) In an Irish context, a recent study ${ }^{7}$ again using PCA, found that PA participation for the 12- to 14-year-old cohort of postprimary Irish children converged into 3 distinct blocks on weekdays ("around school" 8-10 AM and 4-5 PM, "during school" 10-4 PM, and "after school" 5-9 PM) and on weekends ("morning" 8-11 AM, "midday" 11 AM-3 PM, and "afternoon" 3-9 PM). When PA participation in these specific time blocks was investigated according to sex-specific quartiles (representing the least [Q1] to most 
[Q4] active children in terms of MVPA participation), it was found that Q4 males were statistically significantly more active than Q1 and Q2 males in all time periods except for weekend mornings (the least active period overall for males). ${ }^{7}$ A lower variation in MVPA is observed for females than males across quartiles; however, Q4 females were statistically significantly more active than Q1 females in all time periods except the weekend morning. ${ }^{7}$

Taken collectively, the type of information presented in the previously mentioned studies can help point researchers to particular time periods that do not seem compatible with PA for any activity group, highlighting barriers to PA that may exist, and that should potentially be addressed. Such information is invaluable in terms of informing intervention development and structure. However, in review of the previously mentioned studies applying PCA to youth PA, the SES of the participants was not considered. Research including samples from the United Kingdom ${ }^{13}$ and Ireland $^{14}$ suggests that many factors influence lower levels of PA in youth from areas of low SES, including neighborhoods for lower SES groups often being constructed with poorer and fewer recreational facilities ${ }^{14}$ or because of expensive costs for using recreational, sporting, or PA facilities. ${ }^{13}$ In addition, both parents $^{14}$ and children ${ }^{13}$ of low SES perceive their neighborhood as less safe, as is often the reality for low SES neighborhoods, which may discourage children from taking part in activities outdoors or in the evenings. Understanding how some youth manage to achieve the 60 minutes of MVPA/day guidelines in such an environment may be crucial for developing strategies and interventions to help other youth in the same environment to meet this target. Ball et $\mathrm{al}^{3}$ (p1) highlight that "Given the disproportionate burden of ill health carried by people experiencing socioeconomic disadvantage, all our nutrition and physical activity interventions, programs and policies should be designed to reach and positively impact these individuals at greatest need."

The aims of the current study were to investigate (1) patterns of weekday and weekend PA participation in younger children (aged 8-9 y) from areas of social disadvantage and (2) trends across varying time periods based on sex and overall PA level of participants. The study will contribute to a knowledge gap in the patterns of PA in young people, ${ }^{7-9,11,12}$ and in so doing, inform the design of effective interventions for at-risk or vulnerable childhood populations.

\section{Methods}

\section{Participants and Recruitment}

This cross-sectional research was carried out as part of a larger longitudinal clustered randomized control trial called "Sport for Life: All Island," a healthy lifestyle intervention for children aged 8-9 years across the island of Ireland, including both Northern Ireland (NI) and the Republic of Ireland (ROI). Baseline data presented in this article were collected between September/October 2014 and January/February 2015, corresponding with the delivery of Sport for Life: All Island across the island. Ethical approval was granted by the University of Ulster Research Ethics Committee (REC/14/0070).

Primary schools from areas of social and economic deprivation across Ireland were identified using statistical databases and were invited to take part in the study via a letter to the principal. Hindering consistent SES comparability, the 2 jurisdictions, NI and the ROI, do not use one consistent index of deprivation. As such, the measure employed to define deprivation derived from the respective governments within each individual jurisdictions. In NI, all schools included in the Multiple Deprivation Measure 2010 (NIMDM and as such identified by the NI government as being in areas of lower SES) were invited to participate. This database consists of 7 domains of deprivation including income, employment, health, education, proximity to services, living environment, and crime. The schools invited for participation in the ROI were from the Delivering Equality of Opportunity in Schools (DEIS) index. The ROI government identifies schools listed on the DEIS index as disadvantaged because of their socioeconomic conditions and corresponding catchment area. Socioeconomic variables in the DEIS database include local authority accommodation, lone parenthood, travelers, large families (5 or more children), and pupils eligible for free books. From the 98 schools that responded, 27 schools met the inclusion criteria for research which involved (1) schools must have a sports hall and (2) they must be coeducational (include both genders) or have a comparative number of participants in a similar single-gender school. These schools were approached for recruitment through a follow-up phone call with the school principal to confirm their participation. Principals from all 27 primary schools consented to participate (ie, 100\% response rate), with informed parental consent and participant assent subsequently granted for 408 participants. All participants were free to withdraw from the research at any stage.

\section{Procedures}

Body weight (in kilograms) and standing height (to the nearest centimeters) were directly measured using a Seca Portable Height scale and a Seca calibrated heavy-duty scale (Seca Ltd, Hamburg, Germany). Participants were asked to wear an ActiGraph GT1M, GT3X, or GT3X+ accelerometer (ActiGraph LLC, Pensacola, FL) for a period of 8 days on the midaxillary line above their right hip. Data from the $y$-axis on each monitor were used as it has been shown to be comparable across monitors. ${ }^{15}$ Accelerometers were set to record using 5-second epochs. Using ActiLife software, the first day of accelerometer data was omitted from analysis to allow for subject reactivity. ${ }^{16}$ Monitor nonwear was defined as $\geq 20$ consecutive minutes of zero counts. ${ }^{11,16} \mathrm{~A}$ day was deemed valid if there was a minimum of 10 hours recorded wear-time. ${ }^{17}$ The minimum number of valid days required for inclusion in analysis was 3 weekdays and 1 weekend day. ${ }^{18}$ Minutes in MVPA were estimated from the data using the Evenson et al ${ }^{19}$ cut points; MVPA: $\geq 2296$ counts/min.

\section{Data Processing and Analysis}

Mean daily, weekday, and weekend day MVPA were calculated. Sex-specific MVPA quartile cutoff values ${ }^{11}$ were calculated to categorize males and females separately into 4 groups based on daily MVPA representing the least active quartile (Q1) through to the most active (Q4). All data were analyzed using Statistical Package for the Social Sciences (version 20; IBM, Armonk, NY) with alpha set at $P<.05$. To control for potential confounding effects, independent sample $t$ tests were used to identify statistically significant differences in terms of body mass index (BMI) and age between participants who met the accelerometer inclusion criteria and those who did not. Furthermore, in order to control for the potential impact differing methods of determining deprivation between NI and the ROI had on our main variable of interest, an independent samples $t$ test was used to identify if statistically significant differences in daily MVPA between participants from 
the NI and the ROI existed. A 1-way analysis of variance was used to determine if there was any difference in BMI by MVPA sexspecific quartile category. Descriptive analyses were calculated for all variables, and further analyses were then carried out between and within sexes, using paired sample $t$ tests, a multivariate analysis of variance (with Bonferroni adjustment for multiple comparisons), and a chi-square test.

To determine whether specific time blocks during the day contributed more or less to the variation in MVPA, the average minutes of MVPA from each 60-minute block between $8 \mathrm{AM}$ and 9 PM were subjected to a PCA with varimax rotation (employed for ease of interpretation and reporting ${ }^{20}$ and for consistency with previous research ${ }^{8}$ ), analyzed separately for weekday and weekend day. To test if the data set was adequate for factor analysis, a measure of sampling adequacy of Kaiser-Meyer-Olkin was applied. A minimum eigenvalue of 1.0 was used to accept a factor as statistically meaningful. ${ }^{21} \mathrm{~A}$ coefficient of 0.3 or above was considered an important factor loading. ${ }^{20}$ The results of PCA were then used to guide categorization of weekday and weekend day MVPA data into distinct time blocks. Data within each time block were averaged to represent minute/hour of MVPA. A mixed between-within subjects analysis of variance ( 4 groups $\times 7$ time periods) was conducted to assess the impact of quartile grouping on participants' minutes of MVPA across the distinct time blocks; post hoc analysis was carried out with Bonferroni adjustment for multiple comparisons.

\section{Results}

Of the original sample of 408 participants, $213(52 \%)$ met the stringent accelerometer inclusion criteria (thus termed the "valid sample"). Results did not identify any statistically significant differences in terms of BMI or age between the original and valid samples, and as such remaining analyses were carried out on the valid sample only. Participants $(n=213$; male $=54.5 \%)$ were 8.7 (0.5) years and $19.1(4.5) \mathrm{kg} / \mathrm{m}^{2}$. Furthermore, no statistically significant differences were observed in daily MVPA between participants from NI and the ROI. There was no statistically significant difference in BMI for the 4 MVPA sex-specific quartiles: $F(3,201)=1.4, P=.25$.
Overall, $56.7 \%$ met the 60 minutes of MVPA/day guideline (calculated as an average over all valid days); this broke down as $65.5 \%$ of males and $46.4 \%$ of females, with a statistically significantly greater proportion of males meeting the guideline than females, $\chi^{2}(1, \mathrm{n}=213)=7.88, P<.001, \varphi=-0.19$. A statistically significant difference was observed between males and females, with males accumulating statistically significantly more MVPA than females daily $(P=.002)$ and on both weekdays $(P=.01)$ and weekend days $(P=.02)$. No statistically significant difference between weekday and weekend MVPA accumulation was observed either for males (70.13 vs $75.31 \mathrm{~min}$, respectively; $P=.08$ ) or females (61.9 vs 63.62 min, respectively; $P=.54$ ).

Results of the PCA confirmed the factorability of both the weekday and weekend data, with the Bartlett test of sphericity statistically significant in both cases $(P<.001)$, and the KaiserMeyer-Olkin values greater than 0.6 (0.708 weekday and 0.725 weekend). PCA revealed a 3-component solution explaining $51.2 \%$ of variance for weekday data and a 4 component solution explaining $60.4 \%$ of variance for weekend day data. Tables 1 and 2 display the rotated components matrices presenting the loadings for these components for weekday and weekend, respectively. The bold values indicate the time blocks that load strongly on each component. This rotated solution revealed the presence of a simple structure. $^{22}$ Weekday MVPA time blocks were calculated as follows: "morning" 8 to $9 \mathrm{AM}$ and $10 \mathrm{AM}$ to $1 \mathrm{PM}$, "school transitions" 9 to 10 AM and 1 to 2 PM, and "after school" 2 to 9 PM. Weekend time blocks were calculated as: "early morning" 8 to 11 AM, "midday" 11 AM to 1 PM, "afternoon" 1 to 5 PM, and "evening" 5 to 9 PM.

The mean minutes of MVPA/hour within each time block, for each quartile grouping, are presented in Table 3 for males and females, respectively. The row labeled "Q4-Q1" displays the difference in terms of minutes per hour between the most and least active quartiles, while the "total differences" row displays the total difference between the groups when the duration of the time block is taken into account. A statistically significant main effect for time was found for both males $\left(P<.001, \eta_{\mathrm{p}}^{2}=.713\right)$ and females $\left(P<.001, \eta_{\mathrm{p}}^{2}=.748\right)$. Similarly, a statistically significant interaction effect between quartile grouping and time was also found for both males $\left(P<.001, \eta_{\mathrm{p}}^{2}=.273\right)$ and females $\left(P=.04, \eta_{\mathrm{p}}^{2}=.202\right)$. On weekdays, both males and females were statistically

Table 1 Rotated Component Matrix According to Weekday Hourly Time Blocks

\begin{tabular}{|c|c|c|c|c|}
\hline \multirow[b]{2}{*}{ Time block } & \multicolumn{4}{|c|}{ Component } \\
\hline & Mean (SD) & 1 & 2 & 3 \\
\hline 8-9 AM & $4.83(3.43)$ & 0.272 & 0.555 & -0.341 \\
\hline 10-11 AM & $3.06(2.02)$ & -0.088 & 0.484 & 0.083 \\
\hline $11 \mathrm{AM}-12 \mathrm{PM}$ & $2.79(2.15)$ & 0.019 & 0.615 & 0.494 \\
\hline 12-1 PM & $7.46(3.84)$ & 0.043 & 0.597 & -0.023 \\
\hline 9-10 AM & $2.07(2.06)$ & 0.004 & 0.107 & -0.616 \\
\hline 1-2 PM & $3.98(2.7)$ & 0.034 & 0.135 & 0.717 \\
\hline 2-3 PM & $4.64(2.85)$ & 0.466 & 0.405 & -0.086 \\
\hline 3-4 PM & $5.70(3.70)$ & 0.552 & 0.352 & -0.035 \\
\hline 4-5 PM & $6.05(4.01)$ & 0.699 & 0.311 & 0.011 \\
\hline 5-6 PM & $6.58(4.26)$ & 0.767 & 0.107 & 0.042 \\
\hline 6-7 PM & $7.26(4.67)$ & 0.831 & -0.025 & -0.042 \\
\hline 7-8 PM & $6.61(4.46)$ & 0.829 & -0.219 & -0.1 \\
\hline 8-9 PM & $3.45(2.89)$ & 0.644 & -0.314 & 0.217 \\
\hline
\end{tabular}


Table 2 Rotated Component Matrix According to Weekend Hourly Time Blocks

\begin{tabular}{|c|c|c|c|c|c|}
\hline \multirow[b]{2}{*}{ Time block } & \multicolumn{5}{|c|}{ Component } \\
\hline & Mean (SD) & 1 & 2 & 3 & 4 \\
\hline 8-9 AM & $1.48(1.70)$ & -0.058 & -0.002 & -0.07 & 0.775 \\
\hline 9-10 AM & $2.71(3.59)$ & -0.135 & -0.007 & 0.139 & 0.743 \\
\hline 10-11 AM & $5.03(5.07)$ & 0.206 & 0.112 & 0.467 & 0.528 \\
\hline $11 \mathrm{AM}-12 \mathrm{PM}$ & $4.73(5.65)$ & 0.179 & 0.08 & 0.79 & 0.213 \\
\hline 12-1 PM & $5.86(5.95)$ & 0.111 & 0.159 & 0.825 & -0.066 \\
\hline 1-2 PM & $5.86(5.26)$ & 0.665 & -0.099 & 0.214 & -0.13 \\
\hline 2-3 PM & $6.11(5.01)$ & 0.671 & 0.044 & 0.253 & -0.081 \\
\hline 3-4 PM & $6.81(5.78)$ & 0.634 & 0.168 & 0.112 & -0.103 \\
\hline 4-5 PM & $7.22(6.11)$ & 0.723 & 0.279 & -0.164 & 0.202 \\
\hline 5-6 PM & $6.94(6.31)$ & 0.507 & 0.604 & 0.044 & 0.279 \\
\hline 6-7 PM & $6.27(6.00)$ & 0.297 & 0.75 & 0.109 & -0.014 \\
\hline 7-8 PM & $5.43(5.64)$ & 0.102 & 0.819 & 0.184 & -0.102 \\
\hline 8-9 PM & 3.67 (3.94) & -0.09 & 0.638 & 0.019 & 0.057 \\
\hline
\end{tabular}

significantly more active in the morning than during school transitions $(P<.001)$ and were statistically significantly more active after school than during either the morning $(P=.01$ for males and $P=.01$ for females) or school transitions $(P<.001)$. On weekends, males were statistically significantly less active in the early morning than in the afternoon $(P<.001)$ or in the evening $(P=.01)$, while females were statistically significantly less active in the early morning than in the 3 subsequent time periods ( $P=.003, P<.001$, and $P<.001$, respectively).

Statistically significant differences in MVPA accumulated in the different time periods across quartile are shown through annotation in Table 3. Q4 males and females were statistically significantly more active than their Q2 and Q1 counterparts $(P<.05)$ in all time periods other than weekday morning and school transitions. For males, the difference between Q4 and Q1 was greatest in the after-school period on weekdays (equating to a total difference of 49 min across this 7-h time period) and the evening period on weekends (33-min total difference across this 4-h time period). For females, the greatest difference was similarly the after-school period on weekdays (32-min total difference) and the midday period on weekends (11-min total difference across this 2-h time period). The evening period on weekends for females had a total difference of 19 minutes.

\section{Discussion}

In this study, $56.7 \%$ of the 8- to 9-year-old participants met the 60 minutes of MVPA/day guideline. Few studies have measured PA levels of Irish youth from areas of low SES, and there are no published studies that the authors are aware of which have used accelerometry, or worked so specifically with a low SES population; as such it is difficult to draw direct comparisons. Breslin et a ${ }^{23}$ highlight that $21.9 \%$ of children from areas of low SES in NI (8-9 y old) self-reported to meet the 60-minute guideline. While accelerometry was also employed in this study, ${ }^{23}$ cross-sectional data are not presented in a format comparable with the present data set. When we compare the data from the current study to the $42.4 \%$ reported to meet the guideline in Belton et $\mathrm{al},{ }^{7}$ a recent study that applied the same measurement methodology and processing decisions but with an older Irish cohort (12-14 y), we see that the previously reported ${ }^{24}$ age-related decline in PA is evident.
Consistent with previous studies, ${ }^{5-7,9,11,25}$ males were found to accumulate significantly more minutes of MVPA daily, and on weekdays and weekend days than females. The longitudinal study carried out by Brodersen et $\mathrm{al}^{26}$ confirms that an age-related decline and gender disparity in PA level exist irrespective of SES or ethnicity. It is worth noting, however, that while the gender difference in the current study is statistically significant, the effect size $(0.085)$ is relatively small (as measured by $\eta_{\mathrm{p}}^{2}$ ), highlighting that differences between genders are smaller at this younger low SES age group than reported with older children from the general population. ${ }^{7}$ It is also possible that the established larger differences between genders may have been somewhat overestimated when measured by the commonly used self-report method.

In order to discuss findings in terms of time periods, it is useful to describe the Irish primary school day, as the school day can vary quite a bit from country to country. In Ireland, the primary school day runs for 6 hours; however, start and end time can vary from school to school by as much as 1 hour. Some schools may start at 8.30 AM, while another school in the same locality may start at 9.00 $\mathrm{AM}$ and another at 9.30 AM; with all schools finishing at staggered times 6 hours later. (The reason for the staggered start and stop times is generally to reduce traffic congestion in a given area.) This also means that lunch times, typically 30 minutes in duration, vary from school to school. The varied start times helps in large part with understanding and interpreting the "school transitions" period (9-10 AM and 1-2 PM); with different schools having different start times, and thus different lunch times, these two 1-hour blocks capture some of the active transportation and school yard play that takes place immediately before school, along with the lunch time play in the middle of the day.

The most active period of the weekday for both males and females was the after-school period (2-9 PM); this is in contrast to the findings of a study in Canada, ${ }^{12}$ where they found that for 6- to 10-year olds, the school lunchtime (11 AM-12.59 PM) period stood out as the most active. Similarly, in a study by De Baere et $\mathrm{al}^{27}$ involving 10- to 14-year olds in Belgium, researchers found that school time was one of the most active periods for their population. This may likely reflect different approaches to school and lunchtime activities between the school systems in different countries, or indeed different durations of lunchtime breaks, and varying climates across the countries. Consistent with the current 
Table 3 Mean (SD) MVPA for Each Quartile Grouping Within Each Time Period

\begin{tabular}{|c|c|c|c|c|c|c|c|}
\hline \multirow[b]{3}{*}{ Male } & \multicolumn{3}{|c|}{ Weekday } & \multicolumn{4}{|c|}{ Weekend } \\
\hline & Morning $^{\dagger}$ & School transitions & After school ${ }^{\dagger, *}$ & Early morning ${ }^{\star *}$ & Midday $^{\star \star}$ & Afternoon $^{\star \star *, \neq}$ & Evening $^{\star, \neq}$ \\
\hline & $4 \mathrm{~h}$ & $2 \mathrm{~h}$ & $7 \mathrm{~h}$ & $3 \mathrm{~h}$ & $2 \mathrm{~h}$ & $4 \mathrm{~h}$ & $4 \mathrm{~h}$ \\
\hline $\mathrm{Q} 4, \mathrm{~min} / \mathrm{h}$ & $5.38(1.83)$ & $3.55(1.79)$ & $10.13(2.40)$ & $5.74(3.49)$ & $8.77(6.24)$ & $9.90(3.47)$ & $10.85(5.12)$ \\
\hline $\mathrm{Q} 3, \mathrm{~min} / \mathrm{h}$ & $6.19(2.16)$ & $3.12(1.68)$ & $6.11(1.18)$ & $5.02(3.93)$ & $5.24(4.47)$ & $8.39(4.86)$ & $6.05(3.48)$ \\
\hline $\mathrm{Q} 2, \mathrm{~min} / \mathrm{h}$ & $4.95(1.20)$ & $2.82(1.27)$ & $4.56(1.20)$ & $2.58(1.56)$ & $5.44(6.29)$ & $6.28(3.66)$ & $4.85(2.79)$ \\
\hline $\mathrm{Q} 1, \mathrm{~min} / \mathrm{h}$ & $3.55(1.28)$ & $2.80(1.41)$ & $3.17(1.24)$ & $2.49(1.60)$ & $2.66(2.39)$ & $3.53(1.93)$ & $2.72(1.43)$ \\
\hline Total, $\min / \mathrm{h}$ & $5.02(1.91)$ & $3.07(1.56)$ & $6.02(3.05)$ & $4.00(3.19)$ & $5.52(5.48)$ & $7.02(4.32)$ & $6.17(4.61)$ \\
\hline $\mathrm{Q} 4-\mathrm{Q} 1, \mathrm{~min} / \mathrm{h}$ & 1.83 & 0.75 & 6.96 & 3.25 & 6.11 & 6.37 & 8.13 \\
\hline \multirow[t]{3}{*}{ Total differences, $\mathrm{min} / \mathrm{d}$} & 7.32 & 1.5 & 48.72 & 9.75 & 12.22 & 25.48 & 32.52 \\
\hline & \multicolumn{3}{|c|}{ Weekday } & \multicolumn{4}{|c|}{ Weekend } \\
\hline & Morning $^{\star \star \star}$ & School transitions & s After school ${ }^{\star, \neq}$ & $\overline{\text { Early Morning }}{ }^{\star}$ & Midday* & Afternoon* & Evening* \\
\hline Female & $4 \mathrm{~h}$ & $2 \mathrm{~h}$ & $7 \mathrm{~h}$ & $3 \mathrm{~h}$ & $2 \mathrm{~h}$ & $4 \mathrm{~h}$ & $4 \mathrm{~h}$ \\
\hline $\mathrm{Q} 4, \mathrm{~min} / \mathrm{h}$ & $4.90(1.53)$ & $3.21(1.92)$ & $8.05(2.51)$ & $4.49(2.31)$ & $8.63(5.97)$ & $7.97(3.57)$ & $8.12(4.45)$ \\
\hline $\mathrm{Q} 3, \mathrm{~min} / \mathrm{h}$ & $4.20(1.52)$ & $3.04(1.46)$ & $5.79(1.23)$ & $2.64(1.26)$ & $5.13(4.61)$ & $6.33(3.17)$ & $4.84(3.42)$ \\
\hline $\mathrm{Q} 2, \mathrm{~min} / \mathrm{h}$ & $3.40(1.08)$ & $3.13(1.52)$ & $4.62(0.80)$ & $2.44(1.21)$ & $3.66(2.08)$ & $5.30(2.98)$ & $4.01(2.38)$ \\
\hline $\mathrm{Q} 1, \mathrm{~min} / \mathrm{h}$ & $3.37(1.31)$ & $2.31(1.23)$ & $3.41(1.00)$ & $1.66(1.05)$ & $3.21(2.30)$ & $4.07(2.26)$ & $3.32(1.77)$ \\
\hline Total, $\min / \mathrm{h}$ & $3.97(1.50)$ & $2.92(1.57)$ & $5.49(2.28)$ & $2.77(1.78)$ & $5.18(4.56)$ & $5.94(3.31)$ & $5.09(3.64)$ \\
\hline $\mathrm{Q} 4-\mathrm{Q} 1, \mathrm{~min} / \mathrm{h}$ & 1.53 & 0.9 & 4.64 & 2.83 & 5.42 & 3.9 & 4.8 \\
\hline Total differences, $\mathrm{min} / \mathrm{d}$ & 6.12 & 1.8 & 32.48 & 8.49 & 10.84 & 15.6 & 19.2 \\
\hline
\end{tabular}

Abbreviation: MVPA, moderate- to vigorous-intensity physical activity. Note: Total difference = difference between Q4 and Q1 in minutes per hour over total duration of the time block.

$* \mathrm{Q} 4>\mathrm{Q} 3, \mathrm{Q} 2$, and $\mathrm{Q} 1, P<.05 . * * \mathrm{Q} 4>\mathrm{Q} 2$ and $\mathrm{Q} 1, P<.05 . * * * \mathrm{Q} 4>\mathrm{Q} 2, P<.05 .{ }^{\ddagger} \mathrm{Q} 3>\mathrm{Q} 1, P<.05, \dagger \mathrm{Q} 1<\mathrm{Q} 2, \mathrm{Q} 3$ and $\mathrm{Q} 4, P<.05$.

study, De Baere et al $^{27}$ did, however, confirm the early evening period (defined at 3-5 PM) as one of the most active time periods. Though this was with an older age group, it does perhaps confirm the consistent importance of this period immediately after school for PA for both younger and older children, and youth varying levels of disadvantage.

On weekends in the current study, fewer statistically significant differences were observed between time periods; however, students were significantly less active in the early morning period (8-11 AM) than most other weekend periods. This is consistent with the findings of a study with an adolescent cohort, ${ }^{7}$ albeit comprising youth from a general, rather than low SES, population. Given no other studies that we are aware of have investigated weekend day patterns of PA in this way, wider comparisons in this regard are not yet possible. It is probably not surprising that this is the least active period at the weekend, given the children do not have school and parents for the large part may not have work; the day may be a little slower getting started. If we consider the specific cohort in this study, children from schools designated as low SES, we can consider the suggestion made by Stalsberg and Pedersen ${ }^{14}$ also, of parents having less "real spare time." These authors suggest that families from areas of low SES may have to work "unfavorable" jobs, including evening or night shift, as such parents may not be in a position to be up early facilitating PA with their children. ${ }^{14}$

The most active cohort of children in the current study, Q4, were significantly more active than their Q2 and Q1 counterparts in the weekday after-school period (2-9 PM); the period that was also the most active time period of the weekday overall. This was true for both males and females. This is consistent with previous study findings ${ }^{7}$ and again highlights the importance of this period as crucial for PA as identified in other research. ${ }^{27}$ In the current study, Q4 males accumulate close to 49 more minutes of MVPA than Q1 males during what seems to be a critical activity rich 7-hour time period after school. A recent study examining extracurricular PA in Irish adolescent males from areas of low SES, similarly found that those who participate in activities in the after-school period are significantly more active overall and scored more positively on a number of psychosocial subscales. ${ }^{28}$

For females, this weekday after-school figure equates to approximately 33-minute differences between Q4 and Q1 females. These durations compare with figures of 22 and 16 minutes, respectively, for males and females within the adolescent cohort. ${ }^{7}$ While it must be noted that the after-school period was 4 hours long (5-9 PM) in the adolescent study, ${ }^{7}$ when compared with the 7-hour period (2-9 PM) among the younger children in the present study (probably reflecting the longer school day, and the greater homework duration, of the older cohort), we can still consider that the after-school period has arguably a much greater influence on PA levels in this younger age group.

On weekends, we see slightly different patterns emerging between males and females. Q4 males were statistically significantly more active than Q3, Q2, and Q1 males in the weekend evening period and statistically significantly more active than Q2 and Q1 in the remaining 3 weekend time blocks. The weekend time period where we see the largest per hour difference between Q4 and Q1 (8.13 $\mathrm{min} / \mathrm{h}$ ), and also the largest difference overall (32.53 $\mathrm{min}$ ), is the weekend evening period (5-9 PM). This is consistent with the findings of Belton et $\mathrm{al}^{7}{ }^{7}$ where the weekend afternoon period (defined as 3-9 PM) stood out with the greatest difference between Q4 and Q1 males. Q4 females were statistically significantly more active than Q3, Q2, and Q1 females in all weekend time periods. 
Similar to the previous study, ${ }^{7}$ the per hour difference was greatest in the midday period (11 AM-1 PM) for females $(5.42 \mathrm{~min} / \mathrm{h}$, 11-min total difference), while the impact of the total difference between Q4 and Q1 was again greatest in the evening period (5-9 $\mathrm{PM}$, resulting in $19.2 \mathrm{~min}$ overall).

Health inequalities in terms of childhood PA participation in Europe have been well reported. ${ }^{29}$ One study showed that for adolescents, involvement in PA was linked to social class and economic status. ${ }^{30}$ This study further highlighted the need for wider provision of PA in schools in areas of low SES to help ameliorate lower participation levels in this cohort. ${ }^{30}$ A study by Poulton et al highlighted the need for policymakers and researchers to direct resources toward children from areas of low SES, in an effort to protect against the negative health effects of socioeconomic adversity. Recent research ${ }^{7,27,31}$ suggests that it is pertinent to assess trends in childhood PA, particularly as a means of identifying specific contexts for implementing effective interventions (school-based and others). The current study highlights that it is possible for children from areas of low SES to achieve the minimum PA guidelines for health and that the after-school period on weekdays and the midday and evening periods on weekends are the key differentiators between low and high active children in this cohort. As such the authors recommend, in line with Poulton et al, ${ }^{32}$ that resources be directed toward this vulnerable population, with interventions targeting the specific identified time periods previously mentioned, as periods when most improvements can potentially be gained.

\section{Strengths and Limitations}

Strengths of the current study include the use of an objective measure of PA, the diverse number of primary schools and children involved, the inclusion of schools from both the north and south Ireland, and the use of PCA to carry out analysis. Limitations of this study include the fact that only low SES schools were invited to participate, which limits the generalizability of findings, and does not allow for the comparison of findings across general population groups. In addition, the measures used to define low SES were based on the school's location (ie, in NI) or inclusion on the DEIS index list (ie, in the ROI). As such, it is possible that the children's parents may not have resided in a lower strata with regard to their SES. Further research may improve the classification of children's SES by accessing individual-level data, such as parental income, education, or neighborhood living area. Finally, the low level of students meeting the minimum wear-time criteria met for accelerometer $(52 \%)$ inclusion must be acknowledged. While several efforts were made to promote compliance, the low adherence is likely explained because of the stringent but rigorous wear-time criteria applied. It is also worth acknowledging the possibility of other influences on children's PA wear-time adherence and patterns that were not measured in the present study (eg, ethnicity). However, the authors are confident that the valid sample remained representative, given there were no significant differences in age or BMI between the original and valid sample. Further research may consider conducting imputation methods for improving sample size, such as multiple imputation or expectation maximization. ${ }^{20}$

\section{Conclusions}

Results from the present study suggest that the weekday after school, and weekend midday and evening periods may be particularly "activity rich" periods for disadvantaged youth. These are periods when greatest changes can occur and therefore may be advantageous for targeted PA promotion strategies. Future research should extend these findings by determining whether patterns vary by social class and age. In addition, to better inform potential intervention strategies, it would be beneficial to carry out further research determining why some youth choose (or have the opportunity) to be active at specific time periods while others do not and what types of activities specifically they participate in.

\section{Acknowledgments}

The authors would like to acknowledge the contribution of the wider SFL: AI team who were involved in intervention rollout. The authors declare there is no conflict of interest. This work was supported by a grant from the Coca-Cola foundation under Grant 874661.

\section{References}

1. Pulsford RM, Griew P, Page AS, Cooper AR, Hillsdon MM. Socioeconomic position and childhood sedentary time: evidence from the PEACH project. Int J Behav Nutr Phys Act. 2013;10(105):1-9. doi:10.1186/1479-5868-10-105.

2. Drenowatz C, Eisenmann JC, Pfeiffer KA, et al. Influence of socioeconomic status on habitual physical activity and sedentary behavior in 8- to 11-year old children. BMC Public Health. 2010;10(1):214. doi:10.1186/1471-2458-10-214.

3. Ball K. Traversing myths and mountains: addressing socioeconomic inequities in the promotion of nutrition and physical activity behaviours. Int J Behav Nutr Phys Act. 2015;12(142):1-7. doi:10.1186/ s12966-015-0303-4.

4. Williams J, Greene S, Doyle E, et al. Growing Up in Ireland National Longitudinal Study of Children. The Lives of 9-Year Old Children. Report 1. Dublin, Ireland: Economic and Social Research Institute; 2009. http://www.growingup.ie/fileadmin/user_upload/documents/ 1st_Report/Growing_Up_in_Ireland_-_The_Lives_of_9-Year-Olds_ Exec_Summary.pdf. Accessed June 14, 2016.

5. Gavin A, Keane E, Callaghan M, Molcho M, Kelly C, Nic Gabhainn S. The Irish Health Behaviour in School-Aged Children (HBSC) Study 2014. Galway, Ireland: Health Promotion Research Centre; 2015. http:// health.gov.ie/wp-content/uploads/2015/12/HBSC2014web2.pdf. Accessed June 14, 2016.

6. Woods C, Moyna N, Quinlan A, Tannehill D, Walsh J. The Children's Sport Participation and Physical Activity Study (CSPPA Study). Report 1. Dublin, Ireland: Sport Ireland; 2010. https://www4. dcu.ie/shhp/downloads/CSPPA.pdf. Accessed June 14, 2016.

7. Belton S, O'Brien W, Issartel J, McGrane B, Powell D. Where does the time go? Patterns of physical activity in adolescent youth. J Sci Med Sport. 2016;19(11):921-925. PubMed ID: 26897391 doi:10. 1016/j.jsams.2016.01.008

8. Trost SG, Pate RR, Freedson PS, Sallis JF, Taylor WC. Using objective physical activity measures with youth: how many days of monitoring are needed? Med Sci Sports Exerc. 2000;32(2):426-431. http:// europepmc.org/abstract/MED/10694127. Accessed May 14, 2014. PubMed ID: 10694127 doi:10.1097/00005768-200002000-00025

9. Mota J, Santos P, Guerra S, Ribeiro JC, Duarte JA. Patterns of daily physical activity during school days in children and adolescents. Am J Hum Biol. 2003;15(4):547-553. PubMed ID: 12820196 doi:10.1002/ ajhb. 10163

10. DHC. The National Guidelines on Physical Activity for Ireland. Dublin, Ireland: Department of Health and Children; 2009. http://www.getirelandactive.ie/content/wp-content/uploads/2011/12/ Get-Ireland-Active-Guidelines-GIA.pdf. Accessed June 14, 2016. 
11. Fairclough SJ, Boddy LM, Mackintosh KA, Valencia-Peris A, Ramirez-Rico E. Weekday and weekend sedentary time and physical activity in differentially active children. J Sci Med Sport. 2015;18(4): 444-449. PubMed ID: 25011925 doi:10.1016/j.jsams.2014.06.005

12. Garriguet D, Colley R. Daily patterns of physical activity among Canadians. 2012:3-9. http://www.statcan.gc.ca/pub/82-003-x/2012002/ article/11649-eng.pdf. Accessed May 14, 2014.

13. Brockman R, Jago R, Fox KR. Children's active play: self-reported motivators, barriers and facilitators. BMC Public Health. 2011;11: 461. PubMed ID: 21663605 doi:10.1186/1471-2458-11-461.

14. Stalsberg R, Pedersen AV. Effects of socioeconomic status on the physical activity in adolescents: a systematic review of the evidence. Scand J Med Sci Sports. 2010;20(3):368-383. doi:10.1111/j.16000838.2009.01047.x.

15. Sasaki JE, John D, Freedson PS. Validation and comparison of ActiGraph activity monitors. J Sci Med Sport. 2011;14(5): 411-416. PubMed ID: 21616714 doi:10.1016/j.jsams.2011.04.003

16. Esliger DW, Copeland JL, Barnes JD, Tremblay MS. Standardizing and optimizing the use of accelerometer data for free-living physical activity monitoring. J Phys Act Health. 2005;2(1):366-383. doi:10. 1123/jpah.2.3.366

17. Nyberg G, Ekelund U, Marcus C. Physical activity in children measured by accelerometry: stability over time. Scand J Med Sci Sports. 2009;19(1):30-35. PubMed ID: 18248540 doi:10.1111/j. 1600-0838.2007.00756.x

18. Troiano RP, Berrigan D, Dodd KW, Mâsse LC, Tilert T, McDowell M. Physical activity in the United States measured by accelerometer. Med Sci Sports Exerc. 2008;40(1):181-188. PubMed ID: 18091006 doi:10.1249/mss.0b013e31815a51b3.

19. Evenson KR, Catellier DJ, Gill K, Ondrak KS, McMurray RG. Calibration of two objective measures of physical activity for children. J Sports Sci. 2008;26(14):1557-1565. PubMed ID: 18949660 doi:10.1080/02640410802334196

20. Pallant J. SPSS Survival Manual. 3rd ed. New York, NY: McGrawHill; 2007.

21. Kaiser H. A second generation little jiffy. Psychometrika. 1970;35: 401-415. doi:10.1007/BF02291817.

22. Thurstone LL. Multiple Factor Analysis. Chicago, IL: University of Chicago Press; 1947.

23. Breslin G, Gossrau-Breen D, McCay N, Gilmore G, MacDonald L, Hanna D. Physical activity, gender, weight status, and wellbeing in
9- to 11-year-old children: a cross-sectional survey. J Phys Act Health. 2012;9(3):394-401. http://search.ebscohost.com/login.aspx? direct=true $\& \mathrm{db}=$ psyh $\& A N=2012-09143-004 \&$ lang=es \& site=ehostlive. PubMed ID: 21934158 doi:10.1123/jpah.9.3.394. Accessed June 14, 2016.

24. Brooke HL, Atkin AJ, Corder K, Ekelund U, van Sluijs EM. Changes in time-segment specific physical activity between ages 10 and 14 years: a longitudinal observational study. J Sci Med Sport. 2016;19(1):29-34. PubMed ID: 25459234 doi:10.1016/j.jsams.2014.10.003

25. Currie C, Zanotti C, Morgan A, et al. Social Determinants of Health and Well-Being Among Young People. Health Behavior in SchoolAged Children (HBSC) Study: International Report from the 2009/ 2010 Survey. Copenhagen, Denmark: WHO Regional Office for Europe; 2012. http://www.hbsc.unito.it/it/images/pdf/hbsc/prelimspart1.pdf. Accessed August 14, 2014.

26. Brodersen NH, Steptoe A, Boniface DR, Wardle J. Trends in physical activity and sedentary behaviour in adolescence: ethnic and socioeconomic differences. Br J Sports Med. 2007;41:140-144. PubMed ID: 17178773 doi:10.1136/bjsm.2006.031138

27. De Baere S, Lefevre J, De Martelaer K, Philippaerts R, Seghers J. Temporal patterns of physical activity and sedentary behavior in 10-14 year-old children on weekdays. BMC Public Health. 2015; 15(1):791. doi:10.1186/s12889-015-2093-7.

28. Belton S, Prior P, Wickel E, Woods C. The impact of participation in extra-curricular physical activity on males from disadvantaged schools. Eur Phys Educ Rev. 2017;23(1):60-72. doi:10.1177/ 1356336X15625381.

29. WHO. Growing up unequal: gender and socioeconomic differences in young people's health and well-being. Copenhagen, Denmark: WHO Regional Office for Europe; 2016.

30. Dagkas S, Stathi A. Exploring social and environmental factors affecting adolescents' participation in physical activity. Eur Phys Educ Rev. 2007;13(3):369-384. doi:10.1177/1356336X07081800

31. O' Brien W, Issartel J, Belton S. Evidence for the efficacy of the youth-physical activity towards health (Y-PATH) intervention. Adv Phys Educ. 2013;3(4):145-153. doi:10.4236/ape. 2013.34024.

32. Poulton R, Caspi A, Milne BJ, et al. Association between children's experience of socioeconomic disadvantage and adult health: a lifecourse study. Lancet. 2002;360(9346):1640-1645. 